\title{
Excreción de Derivados de Purinas en Función de la Relación Fibra/Proteína en la Dieta de Alpacas (Vicugna pacos)
}

\author{
Purine Derivatives Excretion Function in Relation to the Fiber/Protein Ratio in \\ the Diet of Alpacas (Vicugna pacos)
}

\author{
Viviana Rúa M. ${ }^{1}$, Juan Olazábal L. ${ }^{1,2}$, Felipe San Martín H. ${ }^{1}$
}

\section{Resumen}

\begin{abstract}
El objetivo del presente estudio fue evaluar la relación de la fibra detergente neutro/ proteína cruda sobre la excreción urinaria de derivados de purinas (DP) en alpacas. El diseño experimental fue un cuadrado latino $3 \times 3$. Se utilizaron tres alpacas Huacaya machos de 2.5 años de edad, confinados en corrales individuales. El alimento fue suministrado una vez al día y con agua ad libitum. Se trabajó con tres tratamientos a base de heno de avena, donde las relaciones de fibra/proteína se obtuvieron de acuerdo a las proporciones de tallos y hojas. Los tratamientos fueron: T1, hojas de heno de avena, $58.24 \%$ de fibra detergente neutro (FDN) y $6.80 \%$ proteína cruda (PC); 2 , hojas y tallo de avena, $66.31 \%$ FDN y $6.36 \%$ PC; T3, tallos de avena, $70.22 \%$ FDN y $5.75 \%$ PC. Cada periodo experimental tuvo una duración de 14 días (10 de acostumbramiento y 4 de evaluación). Los niveles de DP en orina se analizaron mediante Cromatografía Líquida de Alto Performance (HPLC). La excreción diaria total de DP fue de 25.51 (T1), 28.07 (T2) y 14.21 (T3) mg/d. La excreción diaria de alantoína, hipoxantina, xantina y la excreción total de DP fue similar entre tratamientos. Los resultados muestran que la relación FDN/PC en los niveles utilizados no tiene influencia sobre la excreción de DP en la orina de alpacas.
\end{abstract}

Palabras clave: alpaca, relación FDN/proteína, derivados de purinas, excreción

\section{Abstract}

The aim of this study was to evaluate the relationship of the neutral detergent fibre/ crude protein on urinary excretion of purine derivatives (PD) in alpacas. The experimental design was a $3 \times 3$ Latin Square. Three male Huacaya alpacas, 2.5 years old, confined in

\footnotetext{
${ }^{1}$ Laboratorio de Bioquímica, Nutrición Animal y Alimentación Animal, Facultad de Medicina Veterinaria, Universidad Nacional Mayor de San Marcos, Lima, Perú

${ }^{3}$ E-mail: jolazaball@gmail.com
}

Recibido: 7 de abril de 2016

Aceptado para publicación: 22 de septiembre de 2016 
individual pens were used. Feed was provided once daily and water ad libitum. Three treatments based on oat hay were used where the ratios of fibre/protein was obtained according to the proportions of stems and leaves. The treatments were: $\mathrm{T} 1$, leaves oat hay, $58.24 \%$ neutral detergent fiber (NDF) and $6.80 \%$ crude protein (CP); T2, leaves and stems of oats, $66.31 \% \mathrm{FDN}$ and $6.36 \% \mathrm{PC}$; T3, stems of oats, $70.22 \% \mathrm{FDN}$ and $5.75 \% \mathrm{PC}$. Each experimental period lasted 14 days, 10 days of adaptation and 4 days of evaluation. The levels of DP urine were analyzed by High Performance Liquid Chromatography (HPLC). The total daily excretion of DP was 25.51 (T1), 28.07 (T2) and 14.21 (T3) mg/d. The daily excretion of allantoin, hypoxanthine, xanthine and the total excretion of DP were similar among treatments. The results showed that the NDF/PC ratio at the levels used does not influence DP excretion in the urine of alpacas.

Key words: alpaca, neutral detergent fiber/crude protein, purine derivatives, excretion

\section{INTRODUCCIÓN}

Los rumiantes se distinguen de otros mamíferos por la adaptación morfofisiológica de la parte anterior de su estómago, que les permite convertir los alimentos fibrosos y proteínas de baja calidad, incluso nitrógeno no proteico (NNP), en ácidos grasos volátiles y proteína microbiana (PM) (Dewhurst et al., 2000). Diversos estudios sobre PM en vacas y otros rumiantes señalan que más del $60 \%$ de los aminoácidos absorbidos por el rumiante derivan de la PM, por lo que es considerada la fuente proteica primaria para estos animales (Muller, 1996).

Los derivados de purina (DP) excretados en la orina son usados para predecir la síntesis de PM en rumiantes; así mismo, en camélidos sudamericanos (CSA) se han realizado experimentos en llamas (Bakker et al., 1996) y alpacas (Rivera, 2004; Orellana et al., 2012), demostrándose la viabilidad de la técnica.

Los CSA son fuente de fibra, carne y trabajo, así como de muchos productos que son indispensables para la subsistencia de un amplio sector de la población altoandina (FAO, 2005). Los CSA presentan características digestivas particulares, como tener una alta eficiencia digestiva con alimentos de baja calidad, debido en parte al mayor tiempo de retención del alimento en el tracto digestivo (San Martin y Bryant, 1989; Fowler, 1998; Sponheimer et al., 2003). Además, pueden reciclar un gran porcentaje de urea a través de la saliva por reabsorción pasiva en los túbulos colectores e ingresar nuevamente al sistema fermentativo, lo cual provee a la población microbiana del nitrógeno necesario, aun cuando la proteína de la dieta sea limitada. A cambio, esta población le otorga al animal una alta calidad de PM (Van Saun, 2006; Cabezas et al., 2007). Los CSA pueden, además, hidrolizar mayor cantidad de urea por unidad de tiempo (mmol $/ \mathrm{h} / \mathrm{kg})$ en el compartimento uno que el bovino y el ovino en el rumen, teniendo como resultado más nitrógeno disponible para la síntesis proteica por los microorganismos (Vallenas, 1991).

La síntesis de PM en el rumen se ve afectada por diversos factores de los alimentos y de los animales. Es conocido que el tipo y cantidad de nutrientes utilizables de la ración, así como la sincronización de la liberación de dichos nutrientes en el rumen, afectan la magnitud de la síntesis microbiana. La energía es el factor más importante que limita la síntesis de PM (Fébel y Fekete, 1996). Las características de la fuente de carbohidratos influyen en la tasa de síntesis microbiana. Las menores tasas de crecimiento microbiano se producen cuando se emplea 
la celulosa como única fuente de energía (Hespell, 1988). Por lo tanto, la relación nivel de fibra y nitrógeno en el alimento afectará directamente la producción de $\mathrm{PM}$, no conociéndose en qué magnitud este factor se manifiesta en los CSA.

Por todo lo antes mencionado, el presente trabajo tuvo como objetivo evaluar la relación fibra/proteína del alimento sobre la excreción urinaria de derivados de purinas (DP) en alpacas.

\section{Materiales y Métodos}

\section{Ubicación del Estudio}

El estudio se realizó en el Fundo «San Marcos» de la Estación Experimental del Centro de Investigación IVITA-Maranganí, a 3727 m de altitud, en el distrito de Maranganí, provincia de Canchis, región Cusco, Perú, con temperatura máxima entre 13 y $14^{\circ} \mathrm{C}$ y con mínima entre -5 y $1.9^{\circ} \mathrm{C}$.

\section{Animales}

Se utilizaron tres alpacas Huacaya, machos, enteros, de dos años y medio de edad, con peso promedio de $48.6 \pm 1.3 \mathrm{~kg}$. Los animales fueron dosificados contra parásitos internos y externos y estabulados individualmente en corrales de $1.5 \times 2 \mathrm{~m}$, provisto de comedero y bebedero, con piso emparrillado que permitía la caída de las heces y orina.

\section{Tratamientos}

El diseño experimental fue de cuadrado latino $3 \times 3$, con tres animales, tres periodos y tres tratamientos. Cada periodo tuvo una duración de $14 \mathrm{~d}$, donde $10 \mathrm{~d}$ fueron de acostumbramiento y los últimos cuatro fueron de toma de información. El alimento utilizado fue heno de avena (Avena sativa), picado a $2 \mathrm{~cm}$ y pasado por un tamiz de $0.4 \mathrm{~cm}$ para separar hojas de tallos y así lograr las distintas proporciones para cada tratamiento. El alimento se suministró una vez al día (08:00) en una cantidad de $700 \mathrm{~g}$ por alpaca/ tratamiento. Los animales tuvieron libre acceso al agua.

Los tratamientos evaluados, según el componente del heno de avena, fueron:

- Tratamiento 1 (T1): hoja, con una relación de fibra detergente neutro y proteína cruda (FDN/PC) de 8.0.

- Tratamiento 2 (T2): hoja (50\%) y tallo (50\%), con una relación de FDN/PC de 10.0 .

- Tratamiento 3 (T3): tallo, con una relación de FDN/PC de 12.0.

\section{Análisis del Alimento}

El heno de avena fue analizado para determinar su contenido de materia seca (MS) y PC, de acuerdo a AOAC (1990) y de FDN, como describe Van Soest et al. (1991).

\section{Muestras de Orina}

El día 10 de cada periodo experimental, se colocó a cada alpaca un arnés con un dispositivo colector de orina antes de ofrecer el alimento y se le mantuvo por cuatro días. El dispositivo estuvo conectado a un recipiente que contenía ácido sulfúrico y agua destilada para mantener el $\mathrm{pH}$ de la orina a niveles inferiores a 3.0 a fin de evitar el crecimiento de agentes bacterianos que destruyan los DP de las muestras (Chen y Gomes, 1992).

Cada mañana, antes de suministrar el alimento diario, se colectó y se midió la cantidad de orina, y se llevó al laboratorio en un frasco de vidrio. Luego, se tomó $1 \mathrm{ml}$ por muestra y se agregó $9 \mathrm{ml}$ de agua purificada. Las muestras fueron almacenadas a $-20^{\circ} \mathrm{C}$.

Los derivados de purina fueron determinados de acuerdo al procedimiento descrito por Chen et al. (1990), donde se cuantificó la concentración molar de xantina, hipoxantina, alantoína, ácido úrico y creatinina. 


\section{Análisis Estadístico}

El efecto de los niveles crecientes de la relación de FDN/PC (tratamientos) sobre la excreción de DP en orina se estimó mediante análisis de varianza para un diseño de cuadrado latino-sobrecambio simple (Steel et al., 1997) con tres filas (periodos), tres columnas (animales) y tres tratamientos.

Se realizó el análisis de regresión lineal entre la excreción total de DP (Y; mg/d) y el consumo de proteína en la dieta $(\mathrm{X} ; \mathrm{g} / \mathrm{d})$, la excreción total de DP (Y; mg/d) y el consumo de FDN en la dieta $(X ; g / d)$ y entre la excreción total de $\mathrm{DP}(\mathrm{Y} ; \mathrm{mg} / \mathrm{d})$ y la relación FDN/PC de la dieta (X). En el análisis estadístico se utilizó SAS/STAT ${ }^{\circledR} 9.2$ (SAS Institute, 2009). En todas las pruebas estadísticas se usó un nivel de significancia de 0.05 .

\section{Resultados y Discusión}

\section{Análisis del Alimento}

En el Cuadro 1 se presenta la composición química de las proporciones de heno de avena utilizados para cada tratamiento en evaluación. Se observa niveles diferenciados de FDN y PC entre tratamientos, confirmando que el proceso de tamizado realizado generó dietas con diferentes niveles de FDN y proteína. El nivel más bajo de PC estuvo en T3 $(5.75 \%)$ y el más alto en T1, que contenía solo hojas de avena $(6.8 \%)$. En forma similar, el menor y mayor valor de FDN se encontró en T1 (hojas) y T3 (tallos), respectivamente.

Los valores de PC y FDN están dentro del rango de la información existente para la avena forrajera (López et al., 2001, Paredes, 2014); sin embargo, el contenido de PC de los tallos (T3) fue mayor del rango encontrado en otros estudios (0.49 a $2.09 \%$ ) donde las partes de la avena fueron separadas ma- nualmente (Cruz, 2007), a diferencia del presente estudio, donde el tamiz puede haber permitido la retención de parte de las hojas con los tallos, y así incrementarse el contenido de PC de los tallos.

En el Cuadro 2 se presenta el consumo por tratamiento. El consumo de MS se mantuvo uniforme en todos los tratamientos a un nivel de $1.65 \%$ del peso vivo. El consumo de FDN fue mayor en T3 (554.7 g) y menor en T1 (460.1 g/d). El consumo de PC fue menor en T3 $(45 \mathrm{~g} / \mathrm{d})$ y mayor en T1 $(54 \mathrm{~g} / \mathrm{d})$. Por otro lado, el consumo de EM fue similar en todos los tratamientos.

Al evaluarse la relación de FDN y PC (Cuadro 2), se observó que los animales T3 consumieron un mayor nivel de FDN por unidad de PC consumida. Por el contrario, la relación PC/EM fue mayor en aquellos animales que consumían hojas (T1) y menor en aquellos alimentados con tallos (T3). Las relaciones de PC/EM del experimento se encuentran dentro del rango de otros reportes (Pardo et al., 2008), donde se trabajó con vacas.

\section{Excreción de Derivados de Purinas}

En el Cuadro 3 se presenta la excreción diaria de DP en la orina de las alpacas. Los DP encontrados fueron alantoína, ácido úrico, hipoxantina y xantina, lo cual concuerda con lo reportado en ovinos (Chen y Gomes, 1992), cabras (Sandoval y Herrera, 1999), alpacas (Rivera, 2004; Orellana et al., 2012) y llamas (Bakker et al., 1996). La diferencia con los DP hallados en vacunos radica en que en estos últimos no excretan hipoxantina y xantina, debido a la alta actividad de la enzima xantina oxidasa en los tejidos e hígado de esta especie (Chen y Gomes, 1992). La determinación de las DP corrobora la información que las alpacas tienen una baja actividad de la enzima xantina oxidasa en los tejidos (Rivera, 2004; Orellana et al., 2012). Se debe resaltar que no se encontró xantina en $\mathrm{T} 2$. 
Cuadro 1. Composición química ${ }^{1}$ del heno de avena preparado de acuerdo a cada tratamiento

\begin{tabular}{lcccc}
\hline Tratamientos & MS & FDN & PC & EM \\
\hline T1 (Hojas) & 91.58 & 58.24 & 6.80 & 1.36 \\
T2 (Hojas y tallo) & 88.51 & 66.31 & 6.36 & 1.31 \\
T3 (Tallo) & 90.72 & 70.22 & 5.75 & 1.34 \\
\hline
\end{tabular}

${ }^{1}$ MS: materia seca (\%); FDN: fibra detergente neutra (\%); PC: proteína cruda (\%); EM: energía metabolizable (Mcal/kg MS)

Cuadro 2. Consumo de materia seca (MS, g/d), fibra detergente neutra (FDN, g/d), proteína cruda $(\mathrm{PC}, \mathrm{g} / \mathrm{d})$ y energía metabolizable $(\mathrm{EM}, \mathrm{Mcal} / \mathrm{d})$, y la relación fibra detergente neutra - proteína cruda y energía-proteína

\begin{tabular}{lcccccc}
\hline Tratamientos & MS & FDN & PC & EM & FDN/PC & PC/EM \\
\hline T1 (hojas) & 790 & 460.1 & 53.72 & 1.007 & 8.57 & 50 \\
T2 (hojas y tallo) & 790 & 523.8 & 50.24 & 1.003 & 10.43 & 49 \\
T3 (tallo) & 790 & 554.7 & 45.43 & 1.005 & 12.21 & 43 \\
\hline
\end{tabular}

Cuadro 3. Excreción diaria de los derivados de purinas $(\mathrm{mg} / \mathrm{d})$ en orina de alpacas con dietas de heno de avena

\begin{tabular}{lccc}
\hline $\begin{array}{l}\text { Derivados de } \\
\text { purinas }\end{array}$ & Hoja & Hoja y tallo & Tallo \\
T1 & T2 & T3 \\
\hline Alantoína & $24.95 \pm 2.37$ & $27.35 \pm 5.17$ & $13.67 \pm 22.00$ \\
Ácido úrico & $0.21 \pm 0.49$ & $0.22 \pm 0.45$ & $0.41 \pm 0.57$ \\
Hipoxantina & $0.27 \pm 0.73$ & $0.50 \pm 1.05$ & $0.01 \pm 0.03$ \\
Xantina & $0.08 \pm 0.28$ & 0 & $0.12 \pm 0.36$ \\
\hline DP total & $25.51 \pm 19.05$ & $28.07 \pm 20.78$ & $14.21 \pm 12.12$ \\
\hline
\end{tabular}

La alantoína se presentó en mayor proporción ( $>96 \%$ ) en todos los tratamientos, tal y como ha sido reportado en alpacas (Rivera, 2004; Orellana et al., 2012) y en llamas (Bakker et al., 1996), donde el orden de abundancia de los DP en orina fue de alantoína, seguido de ácido úrico, xantina y hipoxantina.
Las cantidades de DP encontradas en los tratamientos fueron similares a los valores reportados por Orellana et al. (2012), aunque mayores que los reportados por Rivera (2004) en alpacas. Estas diferencias se deben a que la producción de PM está influenciada por la alimentación, estado fi- 


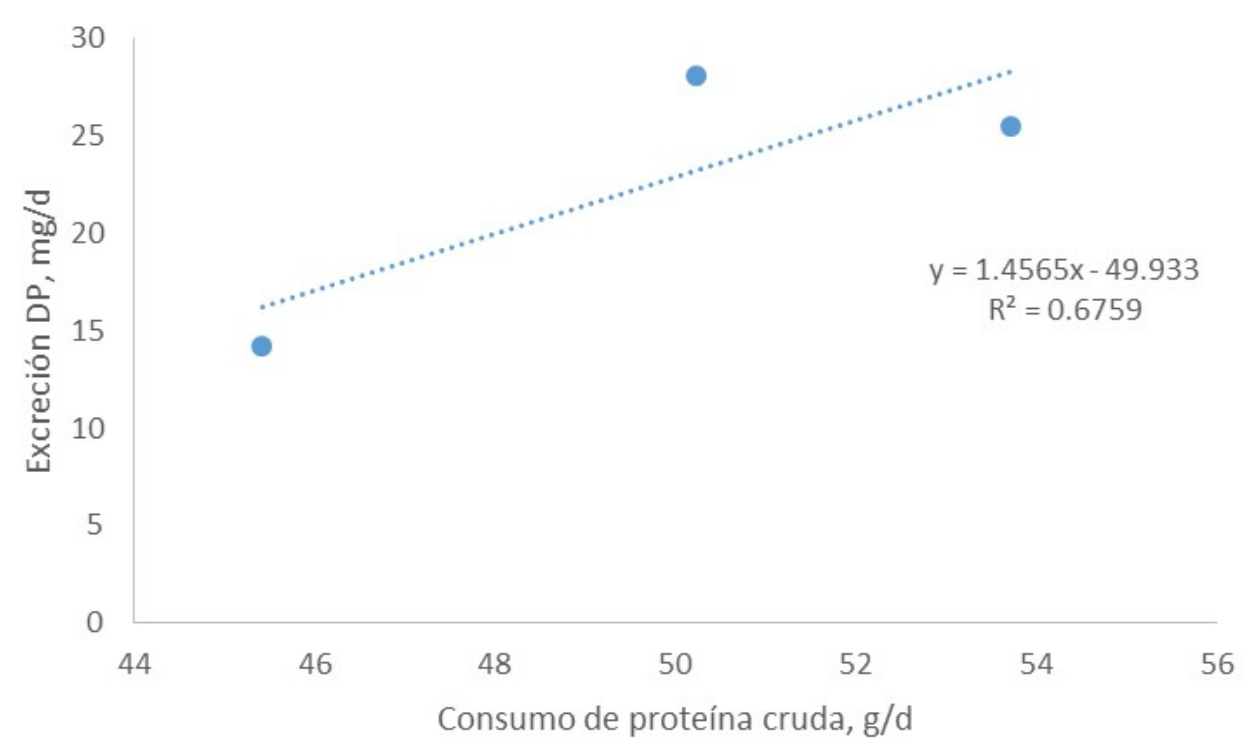

Figura 1. Relación entre excreción total de derivados de purina (mg/d) y consumo de proteína cruda $(\mathrm{g} / \mathrm{d})$ de la dieta en alpacas

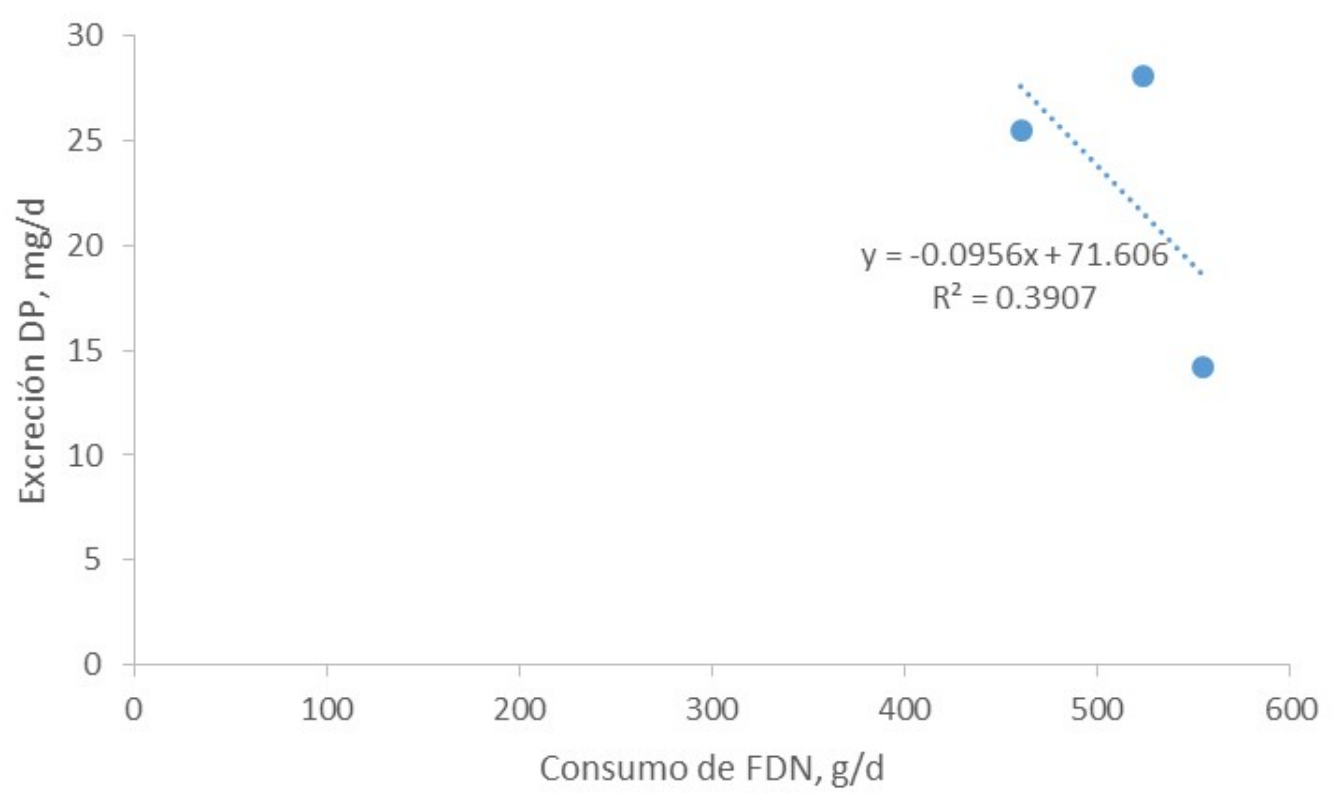

Figura 2. Relación entre excreción total de derivados de purina $(\mathrm{mg} / \mathrm{d})$ y consumo de fibra detergente neutra $(\mathrm{g} / \mathrm{d})$ de las dietas evaluadas 


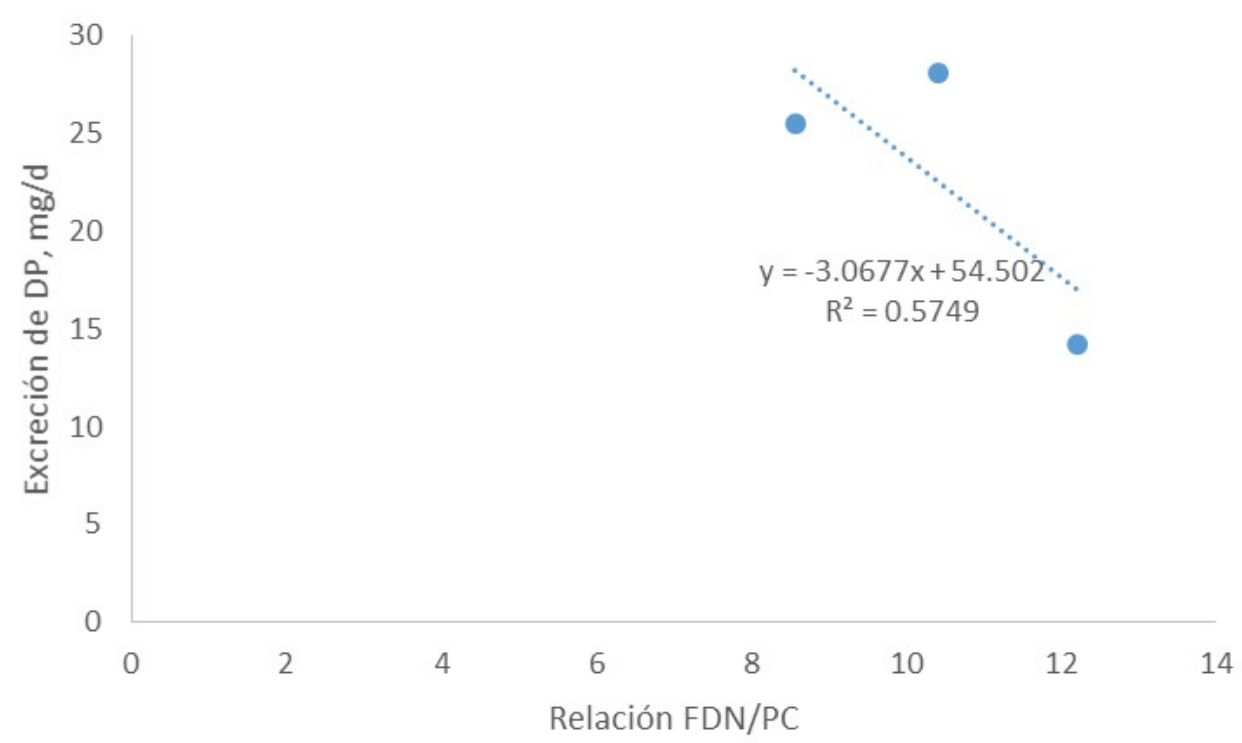

Figura 3 Relación entre excreción total de derivados de purina (mg/d) y la relación FDN/PC

siológico, edad, etc. La información disponible indica que la proporción de alantoína aumenta y el ácido úrico e hipoxantina más xantina disminuyen cuando se incrementa el consumo de materia seca (Chen et al., 1992). No obstante, es importante mencionar que el consumo de materia seca se mantuvo constante en este estudio.

Los resultados indican que la excreción total de DP no estuvo influenciada por la relación FDN/PC, lo cual podría deberse a la alta capacidad de las alpacas para reciclar nitrógeno (San Martín, 1996). Posiblemente, las alpacas de T3, al disponer de un mayor nivel de FDN y menor nivel de PC, tuvieron que disminuir la eliminación renal de urea incrementando su capacidad para reabsorberla (Cirio y Boivin, 1990), previniendo así una reducción excesiva del pool de urea sanguínea. Esta característica, adaptativa tal vez, permitió mantener los niveles necesarios de nitrógeno en el compartimiento 1 para la producción de PM, de allí que al haber un menor consumo de PC fue compensado por un mayor reciclaje de nitrógeno que cuando recibieron un nivel mayor de PC (T1). Sin embargo, se debe tomar en cuenta que en el presente estudio el rango de consumo fue de 45.4 a $53.7 \mathrm{~g} / \mathrm{d}$ de PC para los dos tratamientos extremos, habiendo solo una diferencia de $8 \mathrm{~g}$ de $\mathrm{PC}$ por día.

La relación de FDN/PC se incrementó de $\mathrm{T} 1$ a $\mathrm{T} 3$ pero no hubo diferencias entre las relaciones de PC/EM entre tratamientos. Estas relaciones tan cercanas podrían ser la causa de no haber encontrado diferencias en la cantidad de DP producida entre los tratamientos evaluados.

La Figura 1 presenta la relación lineal entre excreción total de DP (Y; mg/d) y el consumo de proteína cruda por tratamiento $(\mathrm{X} ; \mathrm{g} / \mathrm{d})$, con la ecuación $\mathrm{Y}=1.4553 \mathrm{X}-49.866$ $\left(\mathrm{R}^{2}=0.68\right)$. Se observa que el nivel de proteína contribuye a la excreción total de DP. Este resultado corrobora que la producción de PM está fuertemente influenciada por la cantidad de nitrógeno disponible y el nivel de energía; sin embargo, bajo los niveles evaluados no se pudo encontrar diferencias estadísticas, quizás por el pequeño rango de PC evaluado y la gran eficiencia en la digestión de 
alimentos de mediana y baja calidad, comparados con los ovinos (San Martín y Bryant, 1988). Esto sugiere que los camélidos son más eficientes en el reciclaje de nitrógeno con alimentos de pobre calidad.

En la Figura 2 se muestra la relación lineal entre la excreción total de DP (Y; mg/ d) y el consumo de FDN de cada tratamiento (X; g/d). La ecuación obtenida fue $\mathrm{Y}=-0.0956 \mathrm{X}$ $+71.606\left(\mathrm{R}^{2}=0.40\right)$. Asimismo, en la Figura 3 se presenta la relación entre excreción de derivados de purina (Y; $\mathrm{mg} / \mathrm{d}$ ) y la relación FDN/PC (X), donde la ecuación lineal fue $\mathrm{Y}$ $=-3.0677+54.502\left(R^{2}=0.58\right)$. En ambas ecuaciones se observa un comportamiento similar, donde $\mathrm{T} 2$ presentó mayor excreción de DP. No obstante, se debe tomar en cuenta que solo se están evaluando tres puntos y quizá el modelo lineal utilizado no esté explicando completamente el comportamiento de la función evaluada.

\section{Conclusiones}

- La excreción de derivados de purina en la orina de alpacas no está influenciada por la relación fibra detergente neutro/ proteína cruda.

- Los derivados de purinas: xantina, hipoxantina, ácido úrico y alantoína están presentes en la orina de alpacas.

\section{Literatura Citada}

1. AOAC. 1990. Official methods of analysis of the Association of Official Analytical Chemists. Vol $1.15^{\text {th }}$ ed. Washington DC: AOAC. 1298 p.

2. Bakker ML, Chen XB, Kyle DJ, Orskov ER, Bourke DA. 1996. Urinary and plasma purine derivatives in fed and fasted llamas (Lama glama y $L$. guanicoe). Comp Biochem Physiol B Biochem Mol Biol 113: 367-374. doi: 10.1016/0305-0491(95)02053-5
3. Cabezas O, Giannetto A, Merino M, Piccione. 2007. Seasonal variation of serum urea concentration in alpacas (Lama pacos) housed at three different altitudes. Arch Vet Ital 58(1): 1-6.

4. Chen X.B, Chen YK, Franklin MF, Orskov ER, Shand WJ. 1992. The effect of feed intake and body weight on purine derivative excretion and microbial protein supply in sheep. J Anim Sci 70: 1534-1542. doi: 10.2527/ 1992.7051534x

5. Chen XB, Hovell FD, Orskov ER, Brown DS. 1990. Excretion of purine derivatives by ruminants: effect of exogenous nucleic acid supply on purine derivative excretion by sheep. Br J Nutr 63: 131-142. doi: 10.1079/bjn19900098

6. Chen XB, Gomes MJ. 1992. Estimation of microbial protein supply to sheep and cattle based on urinary excretion of purine derivatives: an overview of the technical details. Scotland: Rowett Research Institute. Occasional publication. 19 p.

7. Cirio A, Boivin R. 1990. Urea recycling from the renal pelvis in sheep: a study with 14C-urea. Am J Physiol 258: F1196F1202.

8. Cruz A. 2007. Estudio de la composición química de espigas, hojas y tallos de avenas cultivadas en Hidalgo y Tlaxcala en los ciclos de cultivo 2003 y 2004. Tesis de Químico en Alimentos. México: Universidad Autonóma del Estado de Hidalgo. $94 \mathrm{p}$.

9. Dewhurst RJ, Davies DR, Merry RJ. 2000. Microbial protein supply from the rumen. Anim Feed Sci Tech 85: 1-21. doi: 10.1016/s0377-8401(00)00139-5

10. [FAOJ Organización de las Naciones Unidas para la Agricultura y la Alimentación. 2005. Situación actual de los camélidos sudamericanos en Perú. Proyecto de Cooperación Técnica en apoyo de la crianza y aprovechamiento de los Camélidos Sudamericanos en la Región Andina TCP/RLA/2914. Lima, Perú. 63 p. 
11. Fébel H, Fekete S. 1996. Factors influencing microbial growth and the efficiency of microbial protein synthesis: a review. Acta Vet Hung 44: 39-56.

12. Fowler M. 1998. Medicine and surgery of South American camelids. Llama, alpaca, vicuña, guanaco. Ames, Iowa, USA: Iowa State University Press. 391 $\mathrm{p}$.

13. Hespell RB. 1988. Microbial digestion of hemicelluloses in the rumen. Microb Sci 5: 362-365.

14. López V, Morales S, Cabrera C, Arias M. 2001. Ingestión y digestibilidad aparente de forrajes por la llama (Lama glama). II. heno de trébol rosado (Trifolium pratense), heno de ballica (Lolium multiflorum), paja de poroto (Phaseolus vulgaris) y paja de avena (Avena sativa). Arch Med Vet 33: 145152. doi: $10.4067 / \mathrm{s} 0301-732 \times 2001000-$ 200003

15. Muller L. 1996. Managing and feeding high merit cows at pasture. In: British Grassland Society Winter Meeting. Grass $\&$ Forage for Cattle of High Genetic Merit. Great Malvern, Great Britain.

16. Orellana-Boero $P$, Seradj A, Fondevila M, Nolan J, Balcells J. 2012. Modelling urinary purine derivatives excretion as a tool to estimate microbial rumen outflow in alpacas (Vicugna pacos). Small Ruminant Res 107: 101-104. doi: 10.1016/j.smallrumres. 2012.04.006

17. Pardo O, Carulla J, Hess H. 2008. Efecto de la relación proteína y energía sobre los niveles de amonio ruminal y nitrógeno ureico en sangre y leche, de vacas doble propósito del piedemonte llanero, Colombia Rev Colomb Cienc Pecu 21: 387-397.

18. Rivera A. 2004. Determinación de la contribución endógena de bases púricas mediante la excreción de derivados púricos marcados con nitrógeno- $15 \mathrm{~N}$ en alpacas (Lama pacos). Tesis de Médico Veterinario. Chillán, Chile: Universidad de Concepción. 38 p.
19. Sandoval-Castro C, Herrera-Gómez F. 1999. Estimación de la síntesis de proteína microbial en rumiantes a través de la medición de los derivados de purina en orina. Rev Biomed 10: 241-251.

20. San Martín F. 1996. Nutrición en alpacas y llamas. Púb. Cient. IVITA N ${ }^{\circ}$ 27. Lima, Perú. 29 p.

21. San Martín F, Bryant FC. 1988. Nutrition of domesticated South American 1lamas and alpacas. Small Ruminant Res 2: 191-216. doi: 10.1016/ 0921-4488(89)90001-1

22. SAS Institute Inc. 2009. SAS/STAT 9.2 User's guide. Cary, NC. 870 p.

23. Sponheimer M, Robinson T, Roeder B, Hammer J, Ayliffe L, Passey B, Cerling T, et al. 2003. Digestion and passage rates of grass hays by llamas, alpacas, goats, rabbits, and horses. Small Ruminant Res 48: 149-154. doi: 10.1016/ s0921-4488(03)00002-6

24. Steel RD, Torrie JH, Dickey DA. 1997. Principles and procedures of statistics: a biometrical approach. $3^{\text {rd }} \mathrm{ed}$. New York: McGraw-Hill. 666 p.

25. Vallenas A. 1991. Características anatomofisiológicas. En: Fernández Baca $\mathrm{S}$ (ed). Avances y perspectivas del conocimiento de los camélidos sudamericanos. Santiago, Chile: FAO. p 121-135.

26. Van Soest PJ, Robertson J, Lewis B. 1991. Methods for dietary fiber, neutral detergent fiber, and nonstarch polysaccharides in relation to animal nutrition. $\mathrm{J}$ Dairy Sci 74: 3583-3597. doi: 10.3168/ jds.s0022-0302(91)78551-2

27. Van Saun R. 2006. Nutrient requeriment of South American Camelids: a factorial approach. Small Ruminnat Res 61: 165186. doi: 10.1016/j.smallrumres. 2005.07.006

28. Verbic JE, Chen XB, Macleod NA, Orskov ER. 1990. Excretion of purine derivatives by ruminants. Effect of microbial nucleic acid infusion on purine derivative excretion by steers. J Agr Sci Camb 114: 243-248. doi: 10.1017/ s0021859600072610 